\title{
A Platform of Constructivist Learning in Practice: Computer Literacy Integrated into Elementary School
}

\author{
doi:10.3991/ijet.v5i2.1040 \\ Garcia, I. ${ }^{1}$, Pacheco, C. ${ }^{2}$, Garcia, G. ${ }^{2}$ \\ ${ }^{1}$ Polytechnic University of Madrid, Spain \\ ${ }^{2}$ Technological University of the Mixtec Region, Mexico
}

\begin{abstract}
In Mexico, the conventional teaching approach, when applied specifically to elementary school, seems to fall short of attaining the overall quality objective. The main consequence of this problem is that teachers are not sure whether their students really understand the dynamic nature of concepts and mechanisms from an early age, particularly in elementary school. This paper presents a pedagogical/technological platform, based on constructivist theories, as a means of making the learning process in elementary school more interesting and effective. The constructivist platform presented here uses graphical simulators developed for Web 2.0 as a support tool, creating a teaching and learning environment in which practical experiments can be undertaken as each topic is introduced and explained.
\end{abstract}

Index Terms-Performance, Design, Reliability, Experimentation, Human Factors, Computer based education, pedagogy, collaborative learning, interactive platform, constructivist theory.

\section{INTRODUCTION}

Nowadays, Latin America is composed of heterogeneous and fragmented societies which live between "pre and post modernity” in relation to education. There is a lack of infrastructure and ideas that make it impossible to bring education to every child; this is unacceptable considering that education is, or should be, one of the main priorities for all countries around the world. However, one of the main challenges in the educational sector has been an increasing demand on services. An improvement in the innovations and achievements of education are necessary in order for Latin America to be able to participate in and benefit from the opportunities offered by better educated and informed societies [9]. However, in spite of this situation, we appear to be unaware of a theory that could provide interaction with the different intellectual capacities of students to improve group learning and, consequently, individual learning; something that has been denominated as 'cooperative learning'.

Cooperative learning theory, an offshoot of constructivism, incorporates the idea that the best learning occurs when students are actively engaged in the learning process and working in collaboration with other students to accomplish a shared goal. While constructivism focuses on personal experience as the foundation for learning new material, cooperative learning utilizes not only the student's own experience to solidify knowledge, but also uses the experiences of others. Both theories emphasize the importance of interactivity with respect to the design and implementation of lesson plans. We attempt to provide a hybrid implementation for engaging teaching at elementary level. The consequence is to increase student learning and motivation as well as instilling a constructivist educational philosophy in the minds of future educators.

Cooperative learning has been used since the 1970s when researchers proposed a variety of approaches and studies to implement cooperative learning techniques with students of different ages and levels. The teacher was responsible for organizing, guiding and recording all the activities of his or her students through support materials such as blackboards, books and templates, amongst other things [7].

At the same time, many psychologists like [3] and [10] affirmed that the learning process was, fundamentally, a social experience where language played a basic role as a mediation tool not only between teacher and student, but also between classmates as well. The students learned how to explain, justify or argue their ideas against other students. According to Vygotsky: “...in a cooperative scenario, the students interchange their ideas, coordinating them to achieve shared objectives. When the problems arise, the combination of activities with communication will conduce to learn" [47]. Thus, the construction process for shared knowledge is a huge help in individual learning. In this sense, cooperative learning is a social activity that involves a student community where knowledge is shared and developed; according to [15], the social construction of knowledge.

Cooperative learning has been defined as the acquisition of knowledge, abilities, and attitudes through the interaction of the group involved. Recently, formal methods in classrooms have been developed and implemented; all of these have the main objective of improving the learning process through learning modules. These modules, physically perceptible, use situation modeling and provide a specific representation of a topic. Usually, the learning modules include experiments in the classroom with demonstrations through oral presentations.

However, collectively, all students have to develop and acquire the necessary skills for working as a team. They have to establish performance methods, generate alternatives, explain, justify and evaluate solutions; this process enables the existence of an effective collaboration [2]. In 
the last decade, IT development has grown dramatically and new forms of social interaction have been created. With these, increasingly new and improved IT systems have been developed with the intention of bettering cooperative interaction among users [21, 1, 40]. Moreover, different educational institutions which have adopted these technologies, have had to implement new methods for learning and teaching. Taking this influence into account and the impact of technological development on society, nowadays our educational institutions are using a new set of technologies for communicating and computing and they are discovering their potential to improve strategic effectiveness in teaching. Amongst them, one line of research that has produced some positive results makes use of the constructivist method of teaching. Besides being well established in other areas, e.g. mathematics, the use of constructivism has many relatively recent works and results in computer science; i.e. [27, 29, 25, 23]. For example, Papert and his colleagues [32, 18, 36], who used the term constructionism to especially stress learning as a (social) design activity, build heavily upon computer science and computer use for learning. As confirmed by others they stress that students construct new knowledge with particular effectiveness when they are engaged in personally meaningful activities. The goals of the teacher are to engage the learner in active participation, problem solving, interdisciplinary work, reflection and discussion.

This paper is organized as follows. Section 2 provides a background to elementary school in Mexico and the motivations for this research. Section 3 describes the constructivist model used to develop our educational platform. Section 4 presents the constructivist platform to be used and evaluated in the daily life of elementary school classrooms. Sections 5 and 6 summarize the experimental results achieved and conclusions from the research respectively.

\section{MEXICAN ElEMENTARY SCHOOL TEACHING}

It is clear that one of the biggest problems in Latin America is education. According to UNESCO in 2006: “...in Latin America, only two of ten students have access to higher education; the other eight do not because of high costs or geographic impossibilities" However, according to another report published by the ONU: "...one of the objectives for 2015, is to accomplish the establishment of universal elementary studies, particularly in developing countries" These statements indicate that there is much work to do for countries like Mexico.

Mexico has been conscious for many decades that one of the requirements needed to provide quality public services for individuals and communities, is to have enough human and material resources to satisfy demand. However, the expansion of the physical infrastructure and human resources used in education has produced a critical reduction in student/teacher ratio. That is, a course in elementary school that consists only of theoretical lectures, does not necessarily guarantee that the students will comprehend and absorb all of the many concepts introduced.

It is essential to reserve part of the academic program for interactive classes and practical exercises. This section presents and discusses the most common practices used in laboratories in many elementary school courses: (1) interactive environments and (2) the use of simulations.

\section{A. Interactive environments}

Some researchers, for example [49, 26, 43], propose teaching in "closed environments" supported by very interactive systems; in most cases, from the perspective of constructivist learning, this method emphasizes the development of students' initiative, cooperative learning, emotion molding, and the growth of their of practical abilities. This is an innovative teaching method with contemporary development trends in teaching patterns. These proposals rely on supervised environments where students maintain direct contact with teachers and platform development by using interactive elements. But as well as the interactive factor, Chepegin et. al. [4] indicate that these environments must have the functionality to change content presentation, links structures or links annotations.

From an educational point of view, interactive environments have many attributes for meaningful learning. For example, they stimulate students' intrinsic motivation to support active learning. According to [22, 23, 24], the characteristics of rules, a challenge, complexity, and practical exercises could foster students' problem solving skills and advance their ability to achieve specific goals. Interactive environments also give immediate feedback, allowing students to reflect straight away on their performance. Furthermore, the friendship or cooperation required among students in this environment promotes social skills. According to [31], all of the characteristics of interactive environments possess the key features of constructivist learning, if matched with the appropriate class content in an adequate learning structure.

\section{B. Use of Simulations}

The key of constructivist theory is that students must be actively involved in the learning process. It is important that Mexican elementary school teachers understand that knowledge acquisition occurs from knowledge that the students already possess, and this differs from student to student. The role of the teacher is to be a guide for the student [14]. We think that simulations could help in this task.

A simulator attempts to create a dynamic and simplified model of reality. We consider that in educational environments, it is potentially far more efficient than other conventional tools. Within Mexico’s elementary schools there are rudimentary simulators supporting the teaching of various disciplines such as mathematics, social sciences, biology, natural sciences, and more. For example: VERMIC [37], KidsPC Professional Educational Software, and the Enciclomedia Project [41] sponsored by the Public Education Secretary.

These rudimentary simulators are simple versions of real environments but this does not necessarily mean that they are always easy to use; each simulator has its own positive and negative characteristics. Also, most of them require considerable time to learn how to use them, and they do not explore the advantages of cooperative learning among young students at elementary school. 


\section{CONSTRUCTIVISM AS A THEORY OF LEARNING}

Jean Piaget is widely recognized as the founding father of constructivism with his notion that learning is individually constructed. Basically, Piaget's observations of how children construct their knowledge have, over the years, formed the basis for his work. Piaget developed many theories, describing the stages of a child's cognitive development. Supported by his extensive research [35], Piaget established an analysis methodology that set the basis for his learning theory: the Genetic Epistemology. However, this idea was not unique to Piaget, many other philosophers having written on the same idea as far back as the $18^{\text {th }}$ century - Vico, and more recently Dewey, Rousseau, Whitehead, Kuhn, Wittgenstein and Rorty [33, 8]. What has emerged in constructivist literature is the bifurcation into two camps of the individual cognitive constructivists (sometimes referred to as psychological constructivism) and the social constructivists [8, 48, 38]. The individual cognitive constructivists focus on the individual's reaction to an experience and to the process through which understandings are formed. Dewey and Piaget describe a similar process in which the individual finds themselves in circumstances where they are uncomfortable and unable to easily explain the situation. New knowledge is then constructed as the individual restructures their knowledge in order to accommodate the new information [8]. Von Glasersfeld discusses radical constructivism as a theory of knowledge and cognition [45] and its applications for teaching [44, 46]. His theory of radical constructivism considers the individual's response as the primary force for knowledge-building; he feels that the social aspects of learning are irrelevant. Conversely, social constructivism places the emphasis on interaction with others; knowledge is seen entirely as a negotiated human construct $[48,38]$. In direct contrast to the radical constructivists, social constructivists believe that you cannot separate one's situation in life from the process of knowledge making [19]. Vygotsky is largely seen as the pioneer in this field with his focus on language; Dewey has also contributed with his description of schools as communities. [34] does an admirable job of describing the evolution of Dewey's thinking as he develops the idea of the classroom as a social unit in which students explore ideas and thus build their own knowledge.

Within the last 20 years, constructivism as a philosophical, epistemological and pedagogical approach has gained a great deal of attention. According to [25], "the classic pedagogic model ${ }^{1}$ at all levels of education is based upon the instructive model, where instructional sequences tackle the task of transferring the maximum amount of information between an active teacher and a passive learner". In general, the Mexican instructive model tends to be standardized and homogenized in the sense that the teaching process is mostly directed to the class as a whole, and not to individuals within the class.

\footnotetext{
${ }^{1}$ The performance models that Mexican teachers use and which determine our educational practice, usually vary from "classical or traditional" to constructivism. The serious problem is that these models are not clear to us and when someone asks: What model do you use in your daily work? teachers do not truthfully respond, either through ignorance or negligence. So, the "classic pedagogic model” is used, which is basically a dictation class taught with a tough regimen of discipline. Students are passive receptors of information, and do not argue or question specific topics, which seriously limits their knowledge acquisition.
}

One way to overcome these limitations imposed by the instructive model is to include concepts from the constructivist theory - the teacher or instructor plays not only the classic role of transmitting knowledge as best s/he can, but also serves as a "facilitator" in the learning process. In the constructivist model the student is the central focus of the whole process of knowledge construction. The development of his or her ability to work cooperatively in groups or teams is as equally relevant as completing tasks for the teacher.

Learning requires self-discipline and building an understanding of conceptual structures through reflection and abstraction. Problems are not solved by the retrieval of rote-learned "right" answers [12]. The constructivist theory stresses the need to understand the child student's thinking and to encourage them to reflect on their models as a means to improve them. Social interaction is an important stimulus for this reflection as well as motivating knowledge construction and adaptation at an early age.

\section{A. A Pedagogic Model based on Constructivism for Elementary School}

In pedagogic models based on the constructivist theory, the student should construct their own knowledge instead of passively absorbing it in a classroom or by consulting text books. Our idea is to develop interactive mechanisms within a constructivist platform under the constructivist model.

Figure 1 shows that this way of learning demands that the student not only discovers the facts, but also creates mental models from them that result in the construction of knowledge. The tasks for monitoring and stimulating the students to achieve their objectives are assigned to teachers, who should be at the same time, conscious of the individual cognitive structures of each student, making this method pedagogically more complex than the classical method.

The Figure 1 model is defined by the following principles:

- Knowledge is not passively received, either by intuition or by communication, but is actively built up by the student.

- The function of cognition is adaptive and tries to increase viability. It serves the organization of the experiential world, not the discovery of ontological reality.

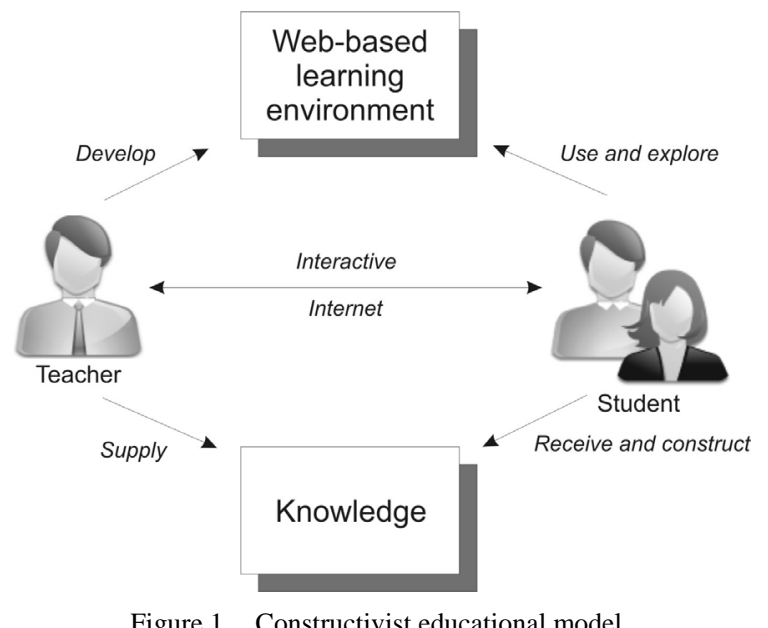

Figure 1. Constructivist educational model. 
Figure 1 acknowledges that learners, including scientists, must construct and reconstruct their own understanding of how the simulated world works, concentrating only on the first principle of the Glasersfeld definition.

The constructivist model recognizes the benefits of students participating in tasks that enable the active construction of their own knowledge domain. In order to do this, we propose the development of a teaching platform based on solid grounding in Piagetian fundamentals. This platform attempts to remodel interaction-type learning with child students against the conventional teaching techniques used in traditional elementary schools. According to Brooks and Brooks [3] and Lin [22] the difference between conventional and constructivist models could be analyzed in physical classrooms (see Table 1), but we think that this could be extended to interactive platforms.

TABLE I.

CONSTRUCTIVIST VERSUS CONVENTIONAL CLASSROOMS

\begin{tabular}{|l|l|}
\hline \multicolumn{1}{|c|}{ Constructivist } & \multicolumn{1}{|c|}{ Conventional } \\
\hline $\begin{array}{l}\text { Students fundamentally work in } \\
\text { groups. }\end{array}$ & $\begin{array}{l}\text { Students fundamentally work } \\
\text { alone. }\end{array}$ \\
\hline $\begin{array}{l}\text { The way that students answer } \\
\text { questions is highly valued. }\end{array}$ & $\begin{array}{l}\text { A high degree of importance is } \\
\text { attached to the established disci- } \\
\text { pline for answering and participat- } \\
\text { ing in the classroom. }\end{array}$ \\
\hline $\begin{array}{l}\text { If a student does not know the } \\
\text { answer, but s/he has an idea, then } \\
\text { they interact with their group and } \\
\text { improve their initial statement. }\end{array}$ & $\begin{array}{l}\text { If a student does not know the } \\
\text { answer, but s/he has an idea, then } \\
\text { they do not make a comment and } \\
\text { avoid interaction. }\end{array}$ \\
\hline $\begin{array}{l}\text { Academic activity is fundamen- } \\
\text { tally based on primary data } \\
\text { sources and computer activities. }\end{array}$ & $\begin{array}{l}\text { Academic activity is fundamen- } \\
\text { tally based on text books and } \\
\text { exercises. }\end{array}$ \\
\hline $\begin{array}{l}\text { Evaluation is related to the teach- } \\
\text { ing process and student's work is } \\
\text { carefully monitored by the } \\
\text { teacher. }\end{array}$ & $\begin{array}{l}\text { Learning process is dissociated } \\
\text { from evaluation and the teaching } \\
\text { process is normally assessed } \\
\text { through tests and exams. }\end{array}$ \\
\hline $\begin{array}{l}\text { Learning emphasis is multi-level } \\
\text { learning for large-scale knowl- } \\
\text { edge and beyond. }\end{array}$ & $\begin{array}{l}\text { Learning emphasis is simple study } \\
\text { for large-scale knowledge. }\end{array}$ \\
\hline $\begin{array}{l}\text { Role of teacher is mainly architect } \\
\text { f facilitator of the classroom situa- } \\
\text { tion. }\end{array}$ & $\begin{array}{l}\text { Role of teacher is mainly speaker } \\
\text { / evaluator. }\end{array}$ \\
\hline $\begin{array}{l}\text { Learning environment is free, } \\
\text { innovative and encouraging. }\end{array}$ & $\begin{array}{l}\text { Learning environment is restric- } \\
\text { tive, formulaic and boring. }\end{array}$ \\
\hline $\begin{array}{l}\text { Focus of evaluation is on experi- } \\
\text { mental results and examination } \\
\text { score. }\end{array}$ & $\begin{array}{l}\text { Focus of evaluation is on experi- } \\
\text { mental process, recalling and } \\
\text { reflection. }\end{array}$ \\
\hline
\end{tabular}

Considering these arguments, we analyzed the Piagetian theory and focused our efforts on the four established stages of children's intellectual development:

- Sensory Motor Stage: from birth to two years old. This is characterized by movements that allow children to focus their activities on determined objectives.

- Pre-operational Stage: seven or eight years old. Language acquisition is the most important event in this period; its development modifies mental structures and relationships with other people. However, the thinking process of the child is still quite egocentric.

- Concrete Operational Stage: eleven and twelve years old. The most representative characteristic of this pe- riod is the child's grasp of the concept of 'reversibility'. That is, the understanding that things are not always as they appear to be.

- Formal Operational Stage: between twelve and thirteen years old. This stage coincides with physical changes and differs from the previous stage in emotional aspects. Children start to reason and evaluate hypothetically, without need to refer to concrete 'real life' evidence.

In this context, we propose a constructivist platform to establish an advantageous interaction between students in the concrete operational stage, and computational tools, that are capable of representing problems that simulate real situations.

\section{A CONSTRUCTIVIST PlatForm}

Many interactive courses for elementary school are based upon teacher presentation and explanation of basic components, rather than allowing the students to develop their own knowledge. This traditional model may turn elementary-level lessons into an extremely theoretical and boring process. The constructivist theory provides an alternative for developing pedagogic proposals, possibly leading to better outcomes in learning than those obtained with traditional instructive models [12, 13, 17].

Our approach proposes a constructivist platform to support the learning process, over which pedagogic models can be developed for discipline at elementary school level. This constructivist platform follows these guidelines:

- The teaching process is conducted in an individualized manner; the teacher should pay close attention to each student's own capacity to assimilate information $[3,26]$.

- The teacher-student interaction has a strong emphasis on searching for practical questions and solutions [11, 22, 43].

- Group work is proposed as an environment in which to achieve cooperative learning [1, 46, 23].

- Students use the constructivist platform in the classroom and homework as a way of recreating situations difficult to generate in real systems $[16,20]$.

- Teachers use the constructivist platform in conjunction with theoretical lessons; complex concepts may be better illustrated [12, 27, 25].

In [16] Jonassen proposed a model for designing constructivist learning environments on the Web, which surround a problem with related cases, information resources that support knowledge construction, cognitive tools, and social contextual support for implementation. Later, in [10] the Jonassen's model was reproduced and modified for designing constructivist environments to improve the learning process through on-line games.

Based on Jonassen's model, we propose an alternative model for developing an interactive platform to implement constructivist learning in elementary schools (see Fig. 2).

The first step in our model is to incorporate the Web 2.0 learning mechanisms with certain characteristics related to the content. Secondly, our model forms an interactive scenario surrounded by tasks, topics, toolbars, games, tests, learning modules, communication interfaces, and a 


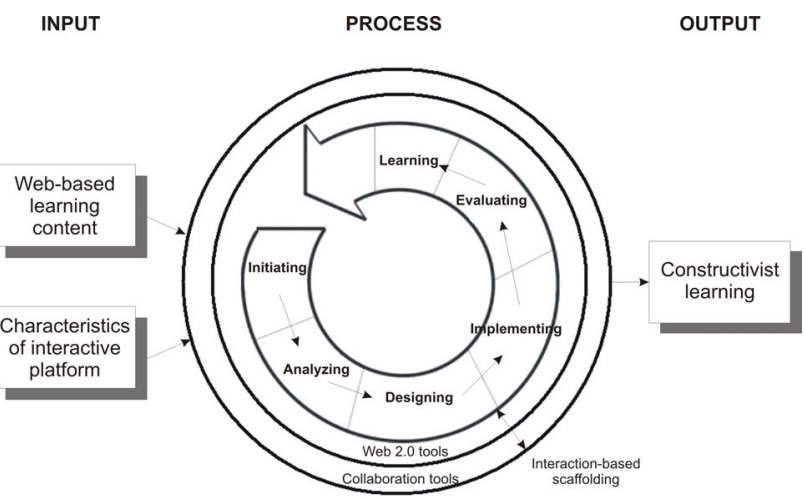

Figure 2. Model for developing interactive platform.

workspace. Also, the model triggers a cycle that includes student evaluations and feedback. Finally, this engagement in interactive platforms means the student is taking part in constructivist learning.

\section{A. Description of our Constructivist Platform}

According to Mayer [28, 42, 30] teaching can include the use of diagrams, high visualization software, or epistemic games -formalized procedures for constructing knowledge. With the aim of producing a high-level interaction platform, our Web application is developed on Flex. Flex is a highly productive, free open-source framework for building and maintaining expressive web applications that deploy consistently on all major browsers, desktops, and operating systems. While Flex applications can be built using only the free open source framework, developers can use Adobe ${ }^{\circledR}$ Flex ${ }^{\circledR}$ Builder ${ }^{\mathrm{TM}}$ software to dramatically accelerate development. Flex provides some adaptation features, for example: adaptive content by wikis, videos or games, and adaptive navigation support by tools and mechanisms.

The interactive platform developed has a constructivist approach, assessing student knowledge and showing content and activities adapted to the characteristics and learning styles of students at elementary school. Besides, the platform allows the students and teachers to autonomously create and consolidate knowledge, with permanent automatic feedback and support, through instructional methodologies and educational activities explored in a constructivist manner.

The constructivist platform is based on progressive selfassessment (interactive exercises, tasks, and more) solved by children that evolve in difficulty and topic. The configuration is set by the teacher but is individualized to each student's level of knowledge, competences, abilities and learning path. The platform is also connected to tutorials that are contextually accessed by the students when they fail a progression step. The constructivist approach also suggests some references to students according to their results in the progressive self-assessment (exercises, tasks, etc.).

The platform provides a set of tools that teachers can configure according to student's intellectual ability:

- Topic browser: The purpose of the browser is for teachers to add or eliminate topics related to the course necessities. The platform includes topics such as mathematics, biology, and history.
- Toolbox: The purpose of the toolbox is to enable the addition or elimination of activities, include elements to interact with the workspace, plan new events and evaluations, and establishment the course sequence.

- Games/Test explorer: The purpose of this explorer is to integrate games or to make periodic evaluations. Games are based on the Adaptive Hypermedia Application Model (AHAM) [6] according to a predefined model of the students that reflects their objectives, preferences, knowledge and competences. Also very important factors in teaching quality control and a necessary part of the teaching process, are exercises and tests which are significant instruments in checking understanding of the learning process. In the process of elementary teaching, games and tests are used to supervise and encourage children to consolidate the knowledge learned.

- Workspace: The workspace is destined for interacting with the course contents or topics. A child student will most interact with hypermedia objects and solve problems in virtual environments like real situations. The primary function of the teaching workspace is to collect, manage and use various teaching resources. The teaching workspace database can be organized according to types of materials, which should be marked so as to facilitate classified storage and retrieval. The establishment of a workspace is an effective way to create a constructivist learning environment.

- Communication Interface: The communication interface provides teachers and students with convenient and practical communication tools. The constructivist platform not only provides students with a message board in each learning activity, to easily raise questions on a specific subject at any time, but also provides a relatively independent and improved question answering system to strongly support the normal operation of teaching activities based on predefined courses.

- Learning Modules: Via learning modules, teachers can assign homework, input and manage test questions and homework, while children can do their homework, self-test, check results and the statistics of certain exercises or performances in the workspace. The main function of the learning modules is to organize the learning resources of platform courses according to certain educational theories, provide testing materials for the making of exercises and the assignment of homework and support the evaluation of students' learning achievements.

- Tutorial wizard: The teaching process under the guidance of the constructivist learning theory is a teacher-led, student-centered teaching mode. The tutorial wizard acts as a guide in learning methods, navigation of information resources, creation of learning scenarios, answering questions and the guidance of student's activity; while student's initiative is reflected in activities such as independent learning, collaboration, discussion, exploration, creation and theme research within the platform resources. 


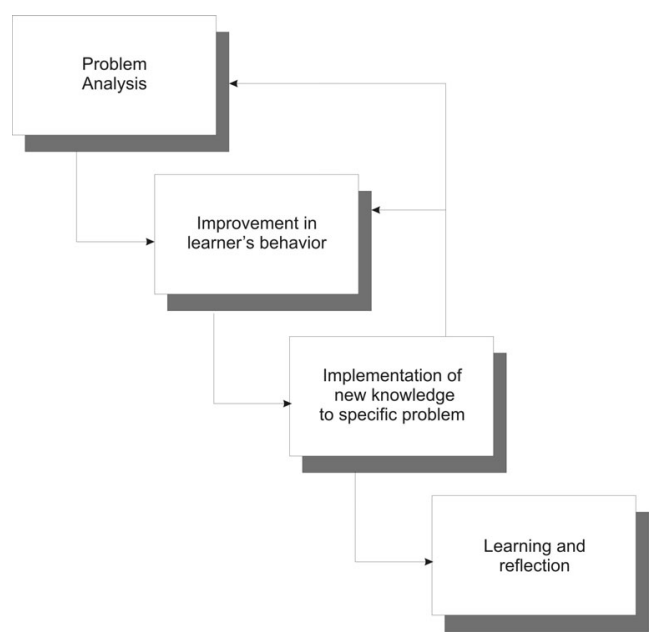

Figure 3. Constructivist learning cycle.

Due to the complexity of knowledge and the difficulties of problem solving in certain situations in the concrete operational stage, it became necessary for the children in our study to carry out collaborative learning in our platform [20]. In such a collaborative learning environment, all the children can share the thoughts and wisdom of the entire learner group; that is, the entire learner group completes the construction of the knowledge learned.

During the collaborative process of learner and teacher, the learner can get guidance from the workspace too, while the teacher can obtain feedback information from the communication interface. In our constructivist platform, collaboration can be carried out between two learners or among many. It can be organized under the teacher's guidance or directly carried out face to face or through online workspace. As shown in Table 1, in the process of collaboration and exploration, by means of a comparative analysis of different points of view on the same problem loaded into the workspace, children can work beyond their own understanding, enriching their knowledge, while improving their capacity to construct meaning in the process of organizing and restructuring various points of view (see Figure 3).

Our platform development is supported by three interrelated models: the student model, the domain model, and the interactive model.

- Student model: This model represents hierarchically the children knowledge. Models for student groups with different levels of knowledge have been used to adapt information, scenarios, goals, plans and to interface. The student plan is a sequence of their actions that achieve a certain goal. The platform observes the children actions and tries to infer all possible plans. This goal is possible because the system possesses a library of all possible children actions and the preconditions of those actions.

- Domain model: This model represents concept hierarchies and the related structure for the representation of a student's level of knowledge (quantitative value). The domain model uses the students' characteristics from the student model. With these functions, it is possible to define the evaluation concept of each student to use in the knowledge acquisition process to "apply" to a specific domain. The evaluation is defined by: the interaction with the student us- ing a progressive assessment; the student knowledge representation defined by the simulation; and the student characteristics.

- Interactive model: The interactive model represents the functionality to change content presentation, the structure of links or the annotation of links with the following objectives for students: to guide them to relevant information and away from irrelevant information or topics that they still would not be able to understand. It uses the technique generally known as link adaptation (hiding, disabling, removal, etc.). Also, the platform supplies, in the content (page), additional or alternative information to certify that the most relevant information is shown. The technique used for this task is generally known as content adaptation. The interactive model is able to use simulations as adaptation technologies to choose the most appropriate content for each student (for example, if a student has a user disability). The constructivist approach is present here, suggesting references and activities to the student according to their results in the progressive self-assessments, exercises, tasks, etc.

The next section illustrates some experimental results supported by real life examples, showing how to use our platform and demonstrating it's suitability for use in elementary schools.

\section{SOME EXPERIMENTAL RESULTS}

An assessment in the "third grade mathematics course" in a public elementary school was performed in two different parts. For this course we were striving to implement a constructivist learning environment and use technological support where appropriate. Our vision for that environment was project-oriented teaching and learning in an internet-supported, collaborative knowledge space, where information resources, inquiry and discussion, as well as intermediate and final results were shared and were accessible as much as possible. So the main concept of this approach was project-based learning (course topics and student motivation), supported by internet-based knowledge sharing (accessibility of information, remote students) and an internet-supported social environment (personal mentors, group collaboration, discussion forums).

The children had to access the platform in a classroom adapted for this, for two sessions per week (two hours each) with teacher guidance, and also for four hours per week from anywhere with access to internet. In order to assess the children's knowledge over six months, we held two short examinations. Results in this examination did not count towards the final exam, although participation in the children's group discussion through workspace was counted. The platform employed a sea simulator to learn more about basic mathematical operations like sums and subtractions. Figure 4 shows a configuration session for adding new students and assigning them into an established group via a rapid evaluation. Teachers must assign a course, the topics and the simulation to use according to the student's age, grade and current level of performance.

A sea simulator was designed because it is a simple method for explaining some concepts related to biology and nature in the same course. The constructivist platform is also able to illustrate theoretical concepts in an intuitive and easy way, allowing the children to construct their own 
mental models of understanding. Currently, three more courses are using this simulator in the mathematics and biology topics. The platform classes take place as soon as the corresponding theory is given in the classrooms. Children work in threes in the computer labs. They work on tasks including practical exercises, specific simulated situations to be analyzed, and some theoretical questions to be answered with the help of the tutorial wizard. As the class evolves, children and the teachers discuss and exchange comments on their workspace results via the communication interface.

\section{A. Project-Based Learning}

Projects in a third-grade math course are related to basic operational problems that could be simplified into the simulation of a real life small project. Work on this project takes place throughout the whole course. First, children receive an assignation from their teachers to finish the project tasks. While the lecture class continues, we then proceed to more advanced concepts in a simulated environment for covering the practical part of the course. The project designated by the teacher has to simulate an overall, real life problem, show concepts of basic mathematical operations, offer sections for learning basic mathematical concepts and has to be sufficiently complex to require (large) interaction with teammates.

The example of Figure 5 shows how children must solve the project tasks. Each selected task from the list should be executed within a simulated environment. According to previous configuration by the teacher, a child can invite one member of his or her team to solve the problems, change the topic and review its results. To provide guidance for beginners, our platform divides each task into three major steps: the first step explains the functionality of the simulation, the second step how to resolve two example problems to learn how to use the environment, and the last step is to solve the problem list.

The screenshot of Figure 5 requires some knowledge of the user interface (simulation, interaction) and further basic concepts related to the domain. Once the child has selected a task, s/he must click the "Continue" button and solve the task indicated by the platform. Figure 6 is an example of a simulation used to resolve the project task. Children communicate via a chat room and interact with the simulated environment according to the platform recommendations.

Evaluation Basing our course on a project-oriented approach, we first asked the children whether they liked the complex project supporting the whole class. The children answered this question very differently: about $20 \%$ did not like the approach at all, while $47 \%$ found it good or very good. Looking more closely, we saw a correlation between the project recommendation and the perceived level of difficulty. Those who did not like the project-based learning approach considered the tasks to be too hard, while those who felt comfortable with it judged the degree of difficulty as appropriate. However, these observations do not currently give enough evidence; we will further investigate this topic in our forthcoming experiments. Furthermore, we will change the conventional lecture to implement project-based lecturing by explaining a complete sample project during one lecture, and adding simulations into related theory areas as needed for the discussed tasks.

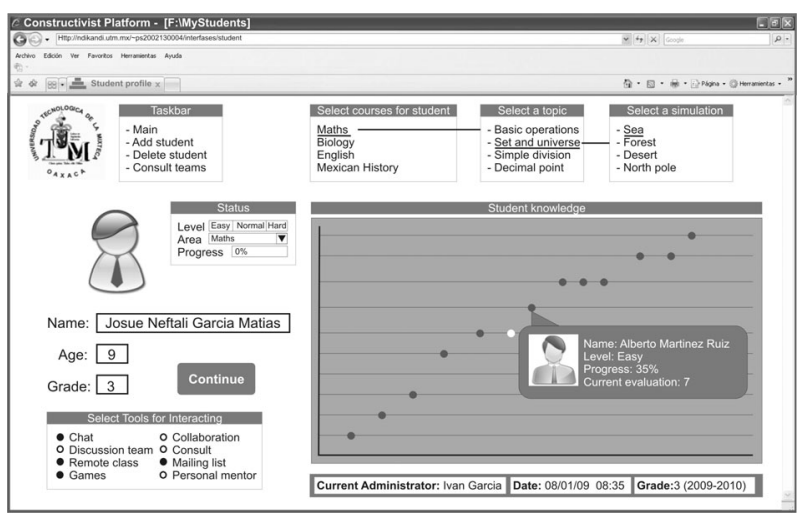

Figure 4. Configuration of the student profile.

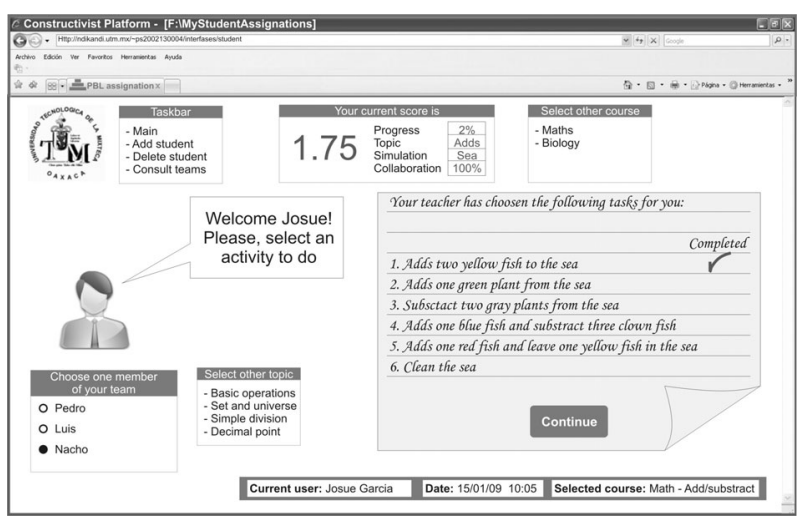

Figure 5. The project based learning configuration.

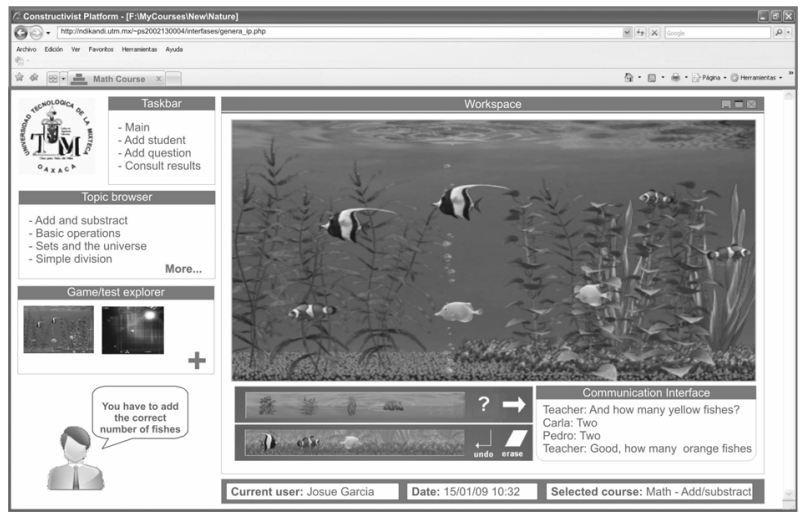

Figure 6. Constructivist platform for elementary schools.

\section{B. Internet-supported social environment}

Project work is done in groups of two or three students each. Our platform supports this work via communication facilities like e-mail, newsgroups, chat rooms, private areas for simulation, and version management facilities. Figure 7 shows that each children group has a personal mentor (a student in a higher grade) who coaches the work of a group and gives help whenever needed. They are always reachable via email or chat. All teachers are also available on e-mail or chat to manage mentor and child work, and to encourage the students to use the opportunity to contact them. According to his or her grade, a child can choose a partner to work with in a simulation session. Teacher and mentor can discuss the student's progress and reconfigure the learning plan. 
Evaluation We asked students about the collaboration in their group and whether they were able to organize their project work. $79 \%$ of the children reported good or very good collaboration in their groups. Difficulties in managing the simulation organization were mentioned by about $31 \%$. Possible reasons for this mentioned by the children include different levels of ability in using a PC and playing games with group members. Collaboration in groups was independent of the endorsement for or against the project approach. The same applied for the work in the learning environment: we did not notice differences in behavior in the way the children used our internetsupported social environment (using e-mail to reach the tutor, participation in discussion newsgroups, using the support for distributed work, e.g. at home, at the school's PC, etc.) The detailed evaluation about the use of e-mail and chat as a communication tool within groups showed that the children preferred face-to-face meetings instead of meeting in a virtual chat space or using electronic mail facilities. This is probably influenced by the situation of the children: they meet each other nearly every day at elementary school in several lectures so they do not need communication support in this way.

\section{Adaptive Links-based knowledge}

In a Web scenario (especially for remote students or for students working mainly at home), all platform information has to be rapidly accessible from different locations. The platform includes a special knowledge base, the Adaptive Links [5]. These links allow navigation based on semantic relationships between single information items of the application domain. Besides this mechanism, Figure 8 illustrates information related to course notes as well as sample projects and a rich set of links to information resources on the platform. Teachers can visually consult the configured projects (including the used simulation) and add a new project with a different simulation. The communication interface enables them to share information about projects and students to establish a new learning plan.

Evaluation During this experiment one group of children had no lecture lessons, only access to the platform and the other resources of our learning environment. There was no difference in their behavior compared with the previous group, although this is not significant because of the small sample. $40 \%$ of the children solved the problems completely on their home PC's, 35\% partially (giving a total of $73 \%$ home users), and the rest worked in school.

\section{Complete assessment}

To back up our evaluations, during 2009, at the end of each class, we solicited both quantitative and qualitative feedback from the students. The main objective was to assess the benefits of the constructivist platform in a traditional teaching environment. The evaluation consisted of eight questions that were submitted to fifty children in the third grade of an elementary school (see Table 2). These questions were graded on the Likert scale [39]: "I disagree”, "Do not agree nor disagree”, "I agree”, "I totally agree”.

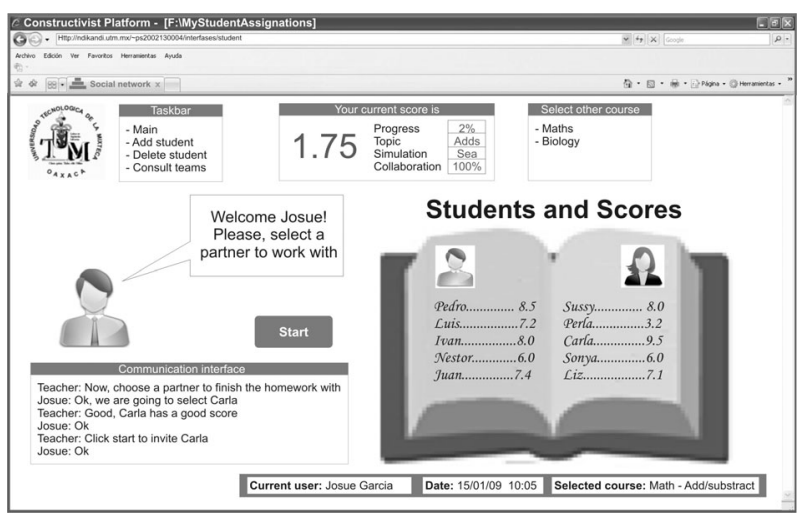

Figure 7. Internet-supported social environment.

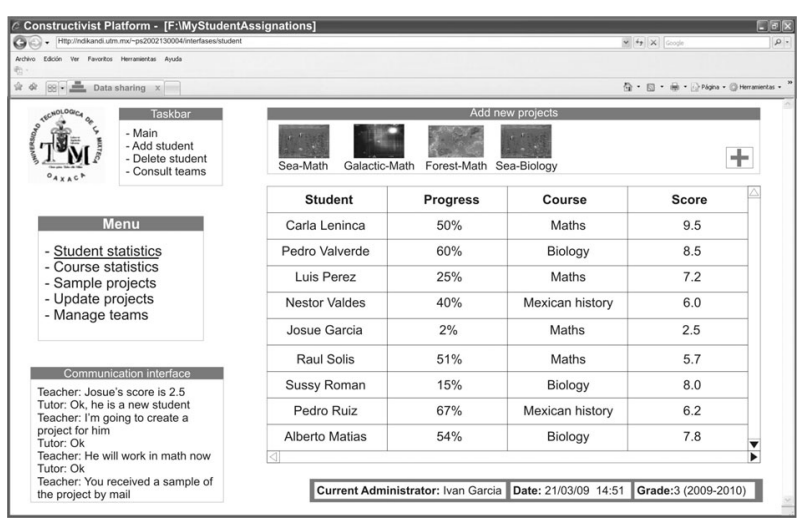

Figure 8. Sharing knowledge with platform.

TABLE II.

EXPERIMENTAL RESULTS

\begin{tabular}{|l|l|l|l|l|}
\hline \multicolumn{1}{|c|}{ Question } & \multicolumn{3}{c|}{ Answer } & $\begin{array}{c}\text { Totally } \\
\text { agree }\end{array}$ \\
\hline $\begin{array}{l}\text { Do not } \\
\text { agree nor } \\
\text { disagree }\end{array}$ & Agree & Disagree & $10.8 \%$ & $88.2 \%$ \\
\hline $\begin{array}{l}\text { Does the constructivist platform } \\
\text { make understanding mathemati- } \\
\text { cal theory and concepts more } \\
\text { satisfying? }\end{array}$ & $\begin{array}{l}\text { Does the constructivist platform } \\
\text { help to motivate you in the sub- } \\
\text { ject? }\end{array}$ & $9.8 \%$ & $45.6 \%$ & $45.6 \%$ \\
\hline $\begin{array}{l}\text { Does the constructivist platform } \\
\text { help your comprehension and } \\
\text { absorption of the mathematical } \\
\text { theories and concepts intro- } \\
\text { duced? }\end{array}$ & $4.1 \%$ & $15.8 \%$ & $80.1 \%$ \\
\hline $\begin{array}{l}\text { Does the constructivist platform } \\
\text { offer a clear and easy interface? }\end{array}$ & $7.5 \%$ & $25.4 \%$ & $54.3 \%$ & $12.8 \%$ \\
\hline $\begin{array}{l}\text { Is the sea simulation adequate for } \\
\text { simulating real situations in } \\
\text { maths and biology? }\end{array}$ & $1.2 \%$ & $5.3 \%$ & $14.6 \%$ & $78.9 \%$ \\
\hline $\begin{array}{l}\text { Is the empirical evidence of } \\
\text { learning in accordance with the } \\
\text { difficulty of the course? }\end{array}$ & $4.2 \%$ & $3.6 \%$ & $46.1 \%$ & $46.1 \%$ \\
\hline $\begin{array}{l}\text { Are the learning perceptions of } \\
\text { students correct? }\end{array}$ & $4.7 \%$ & $20.8 \%$ & $74.5 \%$ \\
\hline $\begin{array}{l}\text { Are the activities implemented in } \\
\text { the constructivist platform re- } \\
\text { lated to real social interactions? }\end{array}$ & $10.5 \%$ & $44.1 \%$ & $44.4 \%$ \\
\hline
\end{tabular}




\section{A Platform of CONSTRUCTIVIST LEARNing in PRACTICE: \\ COMPUTER LITERACY INTEGRATED INTO ELEMENTARY SCHOOL}

In summary, the feedback of Table 2 shows that the majority of the children felt that learning with the constructivist platform was enjoyable, it sparked their interest in the problems, yielded a better comprehension of the mathematical concepts, and made it possible to configure and analyze real situations.

For question five, for example, most children answered that the platform helped them to understand and visualize the mathematical concepts and problems, and also that it narrowed the gap between theory and practice in the classroom. Some children asked for more topics in the platform and some suggested improvements in our first version: "More virtual practices! The platform helps us a lot in understanding the mathematical concepts", "Great job! I thought other games should be introduced to the platform", "The idea is excellent, but the platform characters should be improved”.

\section{CONCLUSIONS}

The constructivist learning theory provides strong theoretical guidance to interactive course design and the development of elementary teaching sources. In this paper we present how the adoption of a constructivist platform opens up excellent opportunities for improvements in teaching and learning processes in elementary schools in Mexico. As in the constructivist platform described above, it provides an illustrated and simplified mechanism to represent and analyze problems and situations, called the workspace. This tool encourages students to build on their knowledge actively and intentionally in authentic contexts. Also, the constructivist platform and communication interface provide feedback that enables students to reflect on the learning process and converse with their teacher and other students. This also means the constructivist learning environment, as described by Jonassen, can be fulfilled by our interactive platform. From an experiment which has been in use at a Central Elementary School in Mexico, the problems due to an unstructured subject, exhibiting a huge gap between theory and practice, were eliminated. However, a qualitative improvement of the whole teaching-learning process is required, and expected.

In our experience, we consider that a big pedagogic advantage in using such a platform, is the construction of a formal teaching-learning environment, where conventional expository lectures, and exercises and simulations with hypermedia objects can be combined. However, it is important to note that our constructivist platform may not follow a formal pedagogic model. The reasoning behind this is that the theoretical principle supporting the model used, is epistemological and not pedagogical. This is a common criticism of Piaget's theories which resides precisely in the absence of a clear and explicit pedagogy line. To avoid this problem, we implement cooperative learning, to apply both in the classroom and in platform work; constructivist thinking can be introduced to support knowledge acquisition, making it possible to experiment with other content.. The use of an interactive platform might also contribute to reducing the total time needed for theory presentation and explanation, perhaps extending the practical sessions, and possibly creating new scenarios for the workspace. Future work will involve refining the proposed constructivist platform as a form of structuring a systematic pedagogical practice for teaching more content at elementary-level school.

\section{ACKNOWLEDGMENTS}

This paper is sponsored by the National Council of Science and Technology and the Technological University of the Mixtec Region.

\section{REFERENCES}

[1] Asif, A. \& Nesbit, J. "Cooperative and online learning in signal processing” Proc. of the IEEE International Conference on Acoustics, Speech, and Signal Processing, ICASSP '01. IEEE Computer Society. pp. 2697-2700. ISBN: 0-7803-7041-4. 2001.

[2] Barros B. \& Verdejo M. "Entornos para la realización de actividades de aprendizaje colaborativo a distancia”, Revista Iberoamericana de Inteligencia Artificial. Num. 12, pp. 39-49. ISSN: 1137-3601. 2001. (in Spanish).

[3] Brooks, J. G. \& Brooks, M. G. "Structuring learning around primary concepts: The quest for essence. In search of understanding: The case for constructivist classrooms” Alexandria, VA: Association for Supervision and Curriculum Development, 1993.

[4] Chepegin, V., Aroyo, L., De Bra, P. \& Heckmann, D. "User Modeling for Modular Adaptive Hypermedia" Proc. of the Workshop on Semantic Web for E-Learning. Eindhoven, Netherlands, pp. 366-371. 2004.

[5] Cobern, W. "Contextual constructivism: The impact of culture on the learning and teaching of science” In Kenneth Tobin (editor). The Practice of Constructivism in Science Education. Lawrence Erlbaum Associates. 1993.

[6] De Bra, P., Houben, G. \& Wu, H. “AHAM: a Dexter-based reference model for adaptive hypermedia” Proc. of the Tenth ACM Conference on Hypertext and hypermedia: returning to our diverse roots. Darmstadt, Germany. pp. 147-156. 1999.

[7] Dillon, J.T. Using discussion in Classrooms, Open University Press. 1994.

[8] Duffy, T. M \& Cunningham, D. “Constructivism: Implications for the design and delivery of instruction” In Jonnasen, D. (ed.) Handbook of research for educational communications and technology, Mahwah, N.J.: Lawrence Erlbaum Associates pp.170-198. 1996.

[9] Elizondo, A., Paredes, F. \& Prieto, A. "ENCICLOMEDIA: Un programa a debate” Revista Mexicana de Investigación Educativa, 11(28): 209-224. Enero-Marzo 2006. (in Spanish).

[10] Finemman, E. \& Bootz, S. "An Introduction to constructivism in Instructional Design” Technology and Teacher Education Annual University of Texas, 1995.

[11] Fu-Hsing, T., Kuang-Chao, Y. \& Hsien-Sheng, H. "Designing Constructivist Learning Environment in Online Game" Proc. of the Digital Game and Intelligent Toy Enhanced Learning, DIGITEL '07. IEEE Computer Society, pp. 212-214. 2007.

[12] Henze, N. \& Nejdl, W. "Constructivism in computer science education: Evaluating a Teleteaching Environment for Project Oriented Learning” Presented in Workshop on Interactive Computer Aided Learning - Concepts and Applications. Villach, Österreich, October 1998.

[13] Hutchison, C. B. "Cultural constructivism: the confluence of cognition, knowledge creation, multiculturalism, and teaching” Intercultural Education, 17(3): 301-310. 2006. doi:10.1080/1467598 0600841694

[14] Jonassen, D. "Objectivism versus constructivism: Do we need a new philosophical paradigm?” Educational Technology, Research and Development, 39(3): 5-14. 1991. doi:10.1007/BF02296434

[15] Jonassen, D., Mayes, T. \& McAleese, R. "A Manifesto for a Constructivist Approach to Uses of Technology in Higher Education”, Designing Environments for Constructive Learning. Duffy, Lowyck \& Jonassen (editors), Springer-Verlag, pp. 231-247. 1992.

[16] Jonassen, D. "Constructivist learning environment on the Web: engaging students in meaningful learning", Paper presented at the Education Technology Conference and Exhibition, 9-11 February, SUNTEC City, Singapore. 1999. 


\section{A Platform of Constructivist LEARNing in PRACTICE:}

\section{COMPUTER LITERACY INTEGRATED INTO ELEMENTARY SCHOOL}

[17] Jonassen, D. “A constructivist's perspective on functional contextualism” Educational Technology Research \& Development, 54(1): 43-47. 2006. doi:10.1007/s11423-006-6493-3

[18] Kafai, Y. \& Resnick, M. Constructionism in Practice: Designing, Thinking and Learning in a Digital World. Lawrence Erlbaum Associates, 1996.

[19] Lewin, P. “Constructivism and Paideia” Radical constructivism in action building on the pioneering work of Ernst Von Glasersfeld. Steffe, L. P. and Thompson, P. W. (eds.) New York: Routledge Falmer. pp. 37-54, 2000.

[20] Li, K. "Teaching design based on cooperative learning under IT" E-education Research, (4): 9-13. 2001.

[21] Lightfoot, J. "Designing and Implementing a "Full-Service" ClassPage on the Internet” Journal of Educational Multimedia and Hypermedia, 9(1): 19-33. Charlottesville, VA. AACE, 2000.

[22] Lin, B. "The Research on Experience Teaching of Marketing Based on Constructivist Learning Perspective” Proc. of the First International Workshop on Education Technology and Computer Science 2009, IEEE Computer Society, pp. 839-843. 2009.

[23] Liu, D., Ma, S., Ru, Q., Guo, Z. \& Ma, S. "Design of Multistrategic Learning Environment based on Constructivism” Proc. of the First International Workshop on Education Technology and Computer Science 2009, IEEE Computer Society, pp. 226-228. 2009.

[24] Luo, H., Li, X. \& Luo, H. "Research on the Design of Network Courses Based on Constructivism” Proc. of the First International Workshop on Education Technology and Computer Science 2009, IEEE Computer Society, pp. 283-287. 2009.

[25] Maia, L., Machado, F. \& Pacheco, A. “A constructivist framework for operating systems education: a pedagogic proposal using the SOsim” Proc. of the 10th annual SIGCSE Conference on Innovation and Technology in Computer Science Education. pp. 218-222, 2005.

[26] Martins, C., Faria, L. \& Carrapatoso, E. "Constructivist Approach for an Educational Adaptive Hypermedia Tool” Proc. of the Eighth IEEE International Conference on Advanced Learning Technologies, IEEE Computer Society, pp. 303-305. 2008.

[27] Matthew, K. \& Kimbell-Lopez, K. "Model Technology Classrooms in Teacher Education". Proc. of the Society for Information Technology and Teacher Education International Conference, pp. 12-15. Chesapeake, VA: AACE. 2000.

[28] Mayer, R. E. "Different problem-solving competencies established in learning computer programming with and without meaningful models" Journal of Educational Psychology, 67(6): 725-734. 1975. doi:10.1037/0022-0663.67.6.725

[29] Mordechai, B. "Constructivism in Computer Science Education” Journal of Computers in Mathematics and Science Teaching, 20(1): 45-73. 2001.

[30] Mulholland, P. Using a fine-grained comparative evaluation technique to understand and design software visualization tools. Paper presented at the Empirical Studies of Programmers: Seventh Workshop. Alexandria, VA. 1997.

[31] Murugaiah, P., Atan, H., Samsudin, D. \& Idrus, R. “The WebBased Learning Environment: A Comparative Study between the Constructivist and Content-Based Approaches” Proc. of the Fourth IEEE International Conference on Advanced Learning Technologies (ICALT'04), IEEE Computer Society, pp.810-812. 2004.

[32] Papert, S. The Children's Machine - Rethinking School in the Age of the Computer. Basic Books, New York, 1993.

[33] Phillips, D. C. "The good, the bad, and the ugly: The many faces of constructivism” Educational Researcher, 24(7): 5-12. 1995.

[34] Phillips, D. C. \& Soltis, J.F. Perspectives on learning. New York: Teachers College Press, 2004.

[35] Piaget, J. Genetic epistemology. New York: Norton. 1970.
[36] Resnick, M. \& Rusk, N. "The computer clubhouse: Preparing for life in a digital world” IBM Systems Journal, 35(4): 431-440. 1996. doi:10.1147/sj.353.0431

[37] Revuelta, F. "On-Line Games and Videogames Educative Power, a New Challenge to Psycho-Pedagogy in the Information Society”, Theoria, 13: 97-102. 2004.

[38] Richardson, V. "Constructivist Pedagogy." Teachers College Record. 105(9): 1623-1640. 2003. doi:10.1046/j.14679620.2003.00303.x

[39] Russell, C. \& Bobko, P. "Moderated Regression Analysis and Likert Scales too Coarse Comfort” Journal of Applied Psychology, 77(3): 336-342. 1992. doi:10.1037/0021-9010.77.3.336

[40] Sala, N. "Cooperative learning and Web applications: a case study" Proc. of the 19th International Conference on Advanced Information Networking and Applications, AINA 2005. IEEE Computer Society, pp. 101-104. ISSN: 1550-445X. 2005.

[41] Sanchez, R. "El Programa Enciclomedia visto por maestros" Revista Mexicana de Investigación Educativa, 11(28): 187-201. 2006. (in Spanish).

[42] Sherry, L. "A model computer simulation as an epistemic game" SIGCSE Bulletin, 27(2): 59-64. 1995. doi:10.1145/2019 $\underline{98.202016}$

[43] Tsai, F-H., Yu, K-C. \& Hsiao, H-S. "Designing Constructivist Learning Environment in Online Game” Proc. of the First IEEE International Workshop on Digital Game and Intelligent Toy Enhanced Learning (DIGITEL'07), IEEE Computer Society, pp. 212214. 2008.

[44] Von Glasersfel, E. Radical Constructivism in Mathematics Education. Mathematics Education Library. Springer; 1st edition. 1991.

[45] Von Glasersfel, E. Radical Constructivism: A Way of Learning. Studies in Mathematics Education Series. Routledge. 1996.

[46] Von Glasersfeld, E. “A constructivist approach to experiential foundations of mathematical concepts revisited” Constructivist Foundations, 1(2): 61-72. 2006.

[47] Vygotsky, L. S. "Mind in society: The development of higher psychological processes” Cambridge MA: Harvard University Press. 1978.

[48] Windschitl, M. "Framing constructivism in practice as the negotiation of dilemmas: An analysis of the conceptual, pedagogical, cultural, and political challenges facing teachers" Review of Educational Research. 72(2): 131-175. 2002. doi:10.3102/00346543 $\underline{072002131}$

[49] Yuanyuan. Z. \& Qian, M. "Research of Constructivism Remote Education Based on Web Mining” Proc. of the First International Workshop on Education Technology and Computer Science 2009, IEEE Computer Society, pp. 440-443. 2009.

\section{AUTHORS}

Garcia, I. (igarcia@zipi.fi.upm.es) is with the Languages and Informatics System and Software Engineering Department, Faculty of Computer Science, Polytechnic University of Madrid, Spain

Pacheco, C. (leninca@mixteco.utm.mx) is with the Postgraduate Department of the Technological University of the Mixtec Region, Mexico, +(953)5320399.

Garcia, G. (ggarcia@mixtli.utm.mx) is with the Technological University of the Mixtec Region, Mexico, + (953) 5320399.

Manuscript received August $14^{\text {th }}$ 2009. Published as resubmitted by the authors May $24^{\text {th }} 2010$. 